Ciência Florestal, Santa Maria, v. 27, n. 1, p. 153-167, jan.-mar., 2017

ISSN 1980-5098

\title{
FITOSSOCIOLOGIA DO COMPONENTE ARBORESCENTE-ARBÓREO DE UMA FLORESTA ESTACIONAL NO VALE DO RIO URUGUAI, SUL DO BRASIL
}

\author{
PHYTOSOCIOLOGY OF THE ARBORESCENT-ARBOREAL COMPONENT OF A SEASONAL \\ FOREST IN URUGUAI RIVER VALLEY, SOUTHERN BRAZIL
}

\author{
Daniel Grasel $^{1}$ Manueli Blatt Spezia ${ }^{1}$ Adriano Dias de Oliveira ${ }^{3}$
}

\begin{abstract}
RESUMO
O status de degradação das florestas no oeste catarinense repercute em um número pequeno de áreas conservadas que possibilitem estudos sobre diversidade e estrutura de comunidades florestais, a fim de criar aporte teórico para estratégias de preservação, manejo e restauração ecossistêmica. O objetivo do presente estudo foi descrever a diversidade e a estrutura de um remanescente de Floresta Estacional Decidual Submontana localizado no município de São João do Oeste - SC. Para o inventário, foram demarcadas 102 unidades amostrais de $10 \times 10 \mathrm{~m}$, dispostas em uma grade contínua de $6 \times 17$ parcelas, nas quais foram amostradas todas as plantas da sinúsia arborescente-arbórea com PAP $\geq 15 \mathrm{~cm}$. Ocorreram 1441,18 árvores vivas e 93,14 plantas mortas em pé/ha. As 79 espécies encontradas pertencem a 61 gêneros e 33 famílias. O índice de diversidade de Shannon $\left(H^{\prime}\right)$ foi de 3,21 e o índice de equabilidade de Pielou $\left(J^{\prime}\right)$ foi de 0,735 . A estrutura vertical da vegetação amostrada foi dividida em arvoretas (2-11 m), dossel (12-17 m) e emergentes $(18-25 \mathrm{~m})$. O remanescente florestal estudado constitui um importante ecossistema de referência para a implementação de estratégias de preservação, manejo e restauração de florestas estacionais.

Palavras-chave: componente lenhoso; estrutura florestal; subformação submontana; Floresta Estacional Decidual.
\end{abstract}

\section{ABSTRACT}

The degradation status of the forests in western Santa Catarina state reflects in a reduced number of conserved areas that enable studies on forest communities diversity and structure in order to create strategies for ecosystems preservation, management and restoration. The objective of this study was to describe the diversity and structure of a forest remnant of Seasonal Submontane Deciduous Forest located in the municipality of São João do Oeste, Santa Catarina state. For the inventory, we demarcated 102 sampling units of $10 \times 10 \mathrm{~m}$, continuously arranged in a grid of $6 \times 17$ plots, in which all plants of the arborescent-arboreal sinusiae with perimeter at breast height $(\mathrm{PBH}) \geq 15 \mathrm{~cm}$ were sampled. We surveyed 1441.18 living trees and 93.14 standing dead plants per ha. The 79 species found belong to 61 genera and 33 families. Sorocea bonplandii, Nectandra megapotamica, Inga marginata, Ocotea diospyrifolia and Trichilia claussenii presented the highest importance value indexes. The Shannon diversity index ( $\left.\mathrm{H}^{\prime}\right)$ was 3.21 and the Pielou equability $(\mathrm{J}$ ') was 0.735 . The vertical structure of the vegetation sampled was divided into treelets $(2-11 \mathrm{~m})$, canopy $(12-17 \mathrm{~m})$ and emerging trees $(18-25 \mathrm{~m})$. The studied forest fragment is an important reference ecosystem for the implementation of strategies for preservation, management and restoration of seasonal forests.

Keywords: woody component; forest structure; submontane subformation; Seasonal Deciduous Forest.

1 Estudante de graduação, curso de Ciências Biológicas, Universidade do Oeste de Santa Catarina, Rua Oiapoc, 211, Bairro Agostini, CEP 89900-000, São Miguel do Oeste (SC), Brasil. graselbio@gmail.com/ manueliblatt@hotmail.com

2 Biólogo, Dr., Professor Adjunto do Departamento de Ciências Biológicas e da Saúde, Universidade do Oeste de Santa Catarina, Rua Oiapoc, 211, Bairro Agostini, CEP 89900-000, São Miguel do Oeste (SC), Brasil. adobiologia@yahoo.com.br

Recebido para publicação em 10/09/2013 e aceito em 19/06/2015

Ci. Fl., v. 27, n. 1, jan.-mar., 2017 


\section{INTRODUÇÃO}

De acordo com Klein (1978), a Floresta Estacional Decidual (FED) cobria originalmente uma área de $7.946 \mathrm{Km}^{2}$ em Santa Catarina, o equivalente a 8\% da superfície do estado, não restando, no ano de 2008, mais do que $16,3 \%$ de sua extensão original (VIBRANS et al., 2013b).

Dentre os tipos florestais que ocorrem no estado catarinense, a FED é o que possui a distribuição mais fragmentada, com $60 \%$ dos remanescentes florestais com área de no máximo 20 hectares (VIBRANS et al., 2012b), enquanto que na Floresta Ombrófila Mista esta porcentagem é de 55\% (VIBRANS et al., 2012c), e na Floresta Ombrófila Densa é de 50\% (VIBRANS et al., 2013).

Além de ser a mais fragmentada, a FED é a menos conhecida e estudada do sul do Brasil (RUSCHEL et al., 2009). Para Santa Catarina, podem ser citados apenas os trabalhos de levantamentos florísticos e de mapeamento fitogeográfico de Klein $(1972 ; 1978)$ e Reitz et al. (1978), e os estudos fitossociológicos publicados por Ruschel et al. (2003; 2005; 2009), Vibrans et al. (2012a) e Schneider e Rocha (2014). Os estudos estruturais na FED catarinense têm amostragens inferiores a 1 ha. Amostragens maiores podem facilitar as discussões sobre estrutura horizontal e vertical na vegetação regional, este último aspecto constituindo caráter fisionômico fundamental na descrição da vegetação (GUREVITCH et al., 2009; JARENKOW; BUDKE, 2009; DURIGAN, 2012), sendo pouco abordado nos estudos fitossociológicos no sul do Brasil.

Ademais, estratégias de restauração de áreas degradadas são comprometidas sem o conhecimento da estrutura e diversidade regional das comunidades florestais, sendo fundamentais os ecossistemas de referência para o planejamento desse processo (ARONSON et al., 1995; DURIGAN et al., 2001; DURIGAN; SOCIETY FOR ECOLOGICAL RESTORATION, 2004; MARTINS, 2009; MARTINS et al., 2012; VIBRANS et al., 2012d).

Nesse contexto, os objetivos deste estudo foram descrever a estrutura horizontal e vertical de um remanescente de floresta conservada no município de São João do Oeste - SC.

\section{MATERIAL E MÉTODOS}

\section{Caracterização da área de estudo}

A área de estudo localiza-se no município de São João do Oeste - SC, com coordenadas centrais da amostra próximas a $27^{\circ} 06^{\prime} 04^{\prime}$ "S e $53^{\circ} 34^{\prime} 32^{\prime}$ W. O remanescente florestal não possui registros e evidências de exploração madeireira, ao contrário do restante da área florestal, que conecta diferentes propriedades particulares. O mesmo se encontra em uma encosta de exposição sudeste, com altitudes que variam entre 347 e 376 m.s.m., na microbacia do rio Macuco, próximo ao divisor de águas que é comum ao rio Fortaleza, ambos afluentes do rio Uruguai (Figura 1).

De acordo com a classificação do IBGE (2012), a formação florestal estudada é de FED, na qual mais de $50 \%$ dos macro e mesofanerófitos perdem as folhas no inverno, quando as temperaturas médias são iguais ou inferiores a $15^{\circ} \mathrm{C}$. Devido à altitude do local de sua ocorrência, é considerada ainda como pertencente à subformação Submontana (FEDS). O dossel é descontínuo (KLEIN, 1984a) e a estrutura vertical é dividida em quatro estratos (arbustos, arvoretas, dossel e emergentes) (KLEIN, 1978).

O clima da região é temperado húmido com verões quentes ( $\mathrm{Cfa}$; temperaturas do mês mais quente $\geq 22^{\circ} \mathrm{C}$; ALVARES et al., 2014). A temperatura média anual é de $20^{\circ} \mathrm{C}$ (PANDOLFO et al., 2002) e a precipitação pluviométrica anual é de $1,900 \mathrm{~mm}$ (PINTO, 2011).

Os solos da região são pouco intemperizados e apresentam atributos muito variáveis. O processo de intemperismo resulta na formação sequencial das seguintes classes de solo: Neossolo Litólico, Cambissolo Háplico e Nitossolo Vermelho, que são típicas de paisagens cujo relevo é ondulado (IUSS WORKING GROUP WRB, 2014).

\section{Método de amostragem}

O inventário da vegetação ocorreu entre agosto de 2012 e fevereiro de 2013. Aplicou-se o método 
de parcelas (MUELLER-DOMBOIS; ELLENBERG, 1974), demarcando-se 102 unidades amostrais de $10 \times 10 \mathrm{~m}$, dispostas em uma grade contínua de $6 \times 17$ parcelas, totalizando 1,02 ha. Optou-se por tal disposição devido à forma do remanescente florestal, que é circundado por vegetação em que ocorreu corte seletivo de árvores.

Todas as plantas arborescente-arbóreas com perímetro a $1,30 \mathrm{~m}(\mathrm{PAP}) \geq 15 \mathrm{~cm}$ foram amostradas. Plantas ramificadas abaixo desta altura foram incluídas somente quando uma das ramificações apresentava PAP $\geq 15 \mathrm{~cm}$, medindo-se então cada uma separadamente para o cálculo da área basal total. As alturas das plantas, inclusive as inclinadas (DURIGAN, 2006), foram medidas por comparação a uma vara de podão de $10,5 \mathrm{~m}$ ou estimadas por visualização quando apresentavam alturas maiores, somente quando não apresentaram copas curvadas ou quebradas.

As espécies foram identificadas a campo ou no laboratório de Zoologia e Botânica da Universidade do Oeste de Santa Catarina (UNOESC), através de coletas de material botânico, que foram incorporadas ao Herbário Fritz Müller (HFM) da instituição. Algumas exsicatas foram encaminhadas a especialistas para a identificação. As espécies foram agrupadas nas famílias reconhecidas pelo "Angiosperm Phylogeny Group" (2009).

\section{Processamento e análise dos dados}

Os parâmetros fitossociológicos calculados foram densidade, frequência e área basal - absoluta e relativa - e os índices de valor de importância e de valor de cobertura (MUELLER-DOMBOIS; ELLENBERG, 1974). A diversidade específica foi determinada através dos índices de Shannon (H') e de equabilidade de Pielou (J'), calculados com base logarítmica neperiana (BROWER; ZAR, 1984), no software Microsoft Office Excel (2013).

A estratificação da floresta foi sugerida através da análise de um gráfico de distribuição de frequências de altura. Para cada estrato (arvoretas, dossel e emergentes) foi calculada a riqueza, a densidade e a área basal relativa de árvores de espécies perenifólias, semidecíduas e decíduas. Para a classificação das espécies quanto à fenologia foliar, foram feitas consultas bibliográficas (KLEIN, 1984a; ATHAYDE et al., 2009; LORENZI, 2009a; 2009b; 2009c) e observações in loco, haja vista a carência de estudos fenológicos publicados realizados no sul do Brasil.

\section{RESULTADOS E DISCUSSÃO}

Foram amostradas 1441,18 plantas vivas e 93,14 plantas mortas em pé por hectare $\left(28,68 \mathrm{~m}^{2}\right.$ e 3,28 $\mathrm{m}^{2}$ de área basal por hectare, respectivamente). Ocorreram 79 espécies arborescente-arbóreas, distribuídas em 61 gêneros e 33 famílias (Tabela 1). Devido à impossibilidade da coleta de material botânico três plantas permanecem indeterminadas.

Das espécies amostradas, Hovenia dulcis é exótica para o Brasil, e Apuleia leiocarpa, Cedrela fissilis e Gleditsia amorphoides enfrentam risco de extinção elevado na natureza (CENTRO NACIONAL DE CONSERVAÇÃO DA FLORA, 2013), sendo que a última raramente é amostrada em inventários fitossociológicos no sul do Brasil.

As famílias mais ricas foram Fabaceae (com 14 espécies), Myrtaceae (oito), Meliaceae (seis), Lauraceae, Salicaceae e Sapindaceae (quatro), que representaram 50,6\% da riqueza total. Os gêneros com a maior quantidade de espécies foram Eugenia L. (cinco), Casearia Jacq., Cordia L. e Trichilia P. Browne (três). O índice de diversidade de Shannon resultou em 3,213 e a equabilidade de Pielou em 0,735.

Em relação a outros estudos realizados com amostras de 1 ha em fragmentos de FED no sul do Brasil (JARENKOW; WAECHTER, 2001; LINDENMAIER; BUDKE, 2006; BUDKE et al. 2007; 2014; GIEHL et al., 2007; GIEHL; JARENKOW, 2008; LEYSER et al., 2009; SCIPIONI et al., 2011; SÜHS; BUDKE, 2011), foram registrados valores acima da média de número de espécies, gêneros e famílias, e dos índices H' e J'. Esses valores podem ter sido influenciados, dentre uma série de outros fatores, pela forma retangular dos 1,02 ha amostrados, uma vez que áreas com esse desenho possuem um maior efeito de borda e representam melhor os efeitos dos gradientes na composição da vegetação do que amostras quadradas ou circulares (FELFILI; CARVALHO; HAIDAR, 2005; FELFILI et al., 2011), portanto, áreas quadradas 

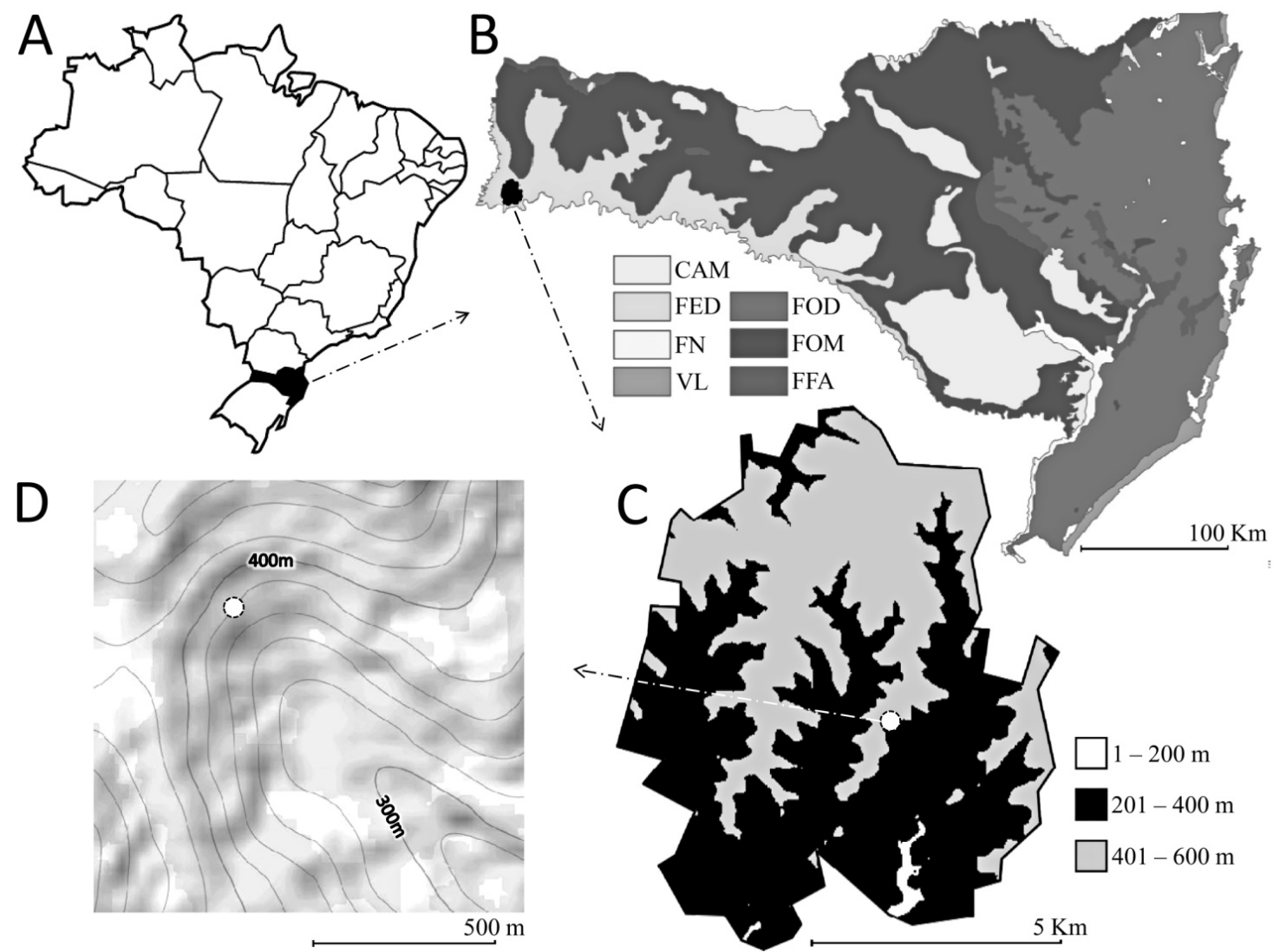

FIGURA 1: Localização da área de estudo. (A) Mapa do Brasil; (B) Mapa Fitogeográfico do Estado de Santa Catarina; (C) Mapa hipsométrico do município de São João do Oeste; (D) Topografia. $\mathrm{CAM}=$ campos; $\mathrm{DEF}=$ Floresta Estacional Decidual; FN = Floresta Nebular; VL = Vegetação Litorânea; FOD = Floresta Ombrófila Densa; FOM = Floresta Ombrófila Mista; FFA = Floresta de Faxinais (Adaptado e modificado de SOUZA et al., 2012).

FIGURE 1: Location of the study area. (A) Map of Brazil; (B) Phytogeographical map of the state of Santa Catarina; (C) Hypsometric map of the municipality of São João do Oeste; (D) Topography. $\mathrm{CAM}=$ Fields; $\mathrm{DEF}=$ Seasonal Deciduous Forest; $\mathrm{FN}=$ Nebular Forest; $\mathrm{VL}=$ Coastal Vegetation; FOD $=$ Ombrophilous Dense Forest; FOM = Ombrophilous Mixed Forest; FFA = Faxinal Forests (Adapted and modified from SOUZA et al., 2012).

tendem a descrever melhor a estrutura e formas retangulares a variação na vegetação (ODA-SOUZA et al., 2010), o que pode ajudar a explicar o fato de a curva espécies/área não ter mostrado tendência à estabilização (Figura 2), sendo que a partir da $51^{\circ}$ parcela, 17 espécies (22\%) foram acrescidas.

A elevada riqueza específica de Fabaceae se repete em outros estudos geograficamente próximos, como em Leyser et al. (2009), Scipioni et al. (2011) e Giehl e Jarenkow (2008), que inventariaram 10, 14 e 16 espécies, respectivamente. Fabaceae se destaca pela elevada quantidade de espécies que alcançam o Rio Grande do Sul pela rota de migração das bacias dos rios Paraná e Uruguai (RAMBO, 1961), sendo que grande parte das espécies emergentes e caducifólias da FED pertence à família (KLEIN, 1984a; REITZ et al., 1988; VELOSO et al., 1991; IBGE, 2012), contribuindo para a caracterização fisionômica (KLEIN, 1978) e para a denominação da formação florestal (LEITE, 2002).

As famílias com as maiores abundâncias foram Moraceae, Fabaceae, Meliaceae e Euphorbiaceae, que tiveram como espécies mais abundantes, respectivamente, Sorocea bonplandii, Inga marginata, Trichilia claussenii e Actinostemon concolor, as quais totalizaram 49,5\% das plantas amostradas. De acordo com Klein (1984b) e Smith et al. (1988), com exceção de Inga marginata e a adição de Allophylus edulis, essas 
TABELA 1: Parâmetros fitossociológicos das espécies amostradas em um remanescente florestal no município de São João do Oeste - SC. Tabela em ordem decrescente de IVI (índice de valor de importância). $\mathrm{NC}=$ número do coletor; $\mathrm{FF}=$ fenologia foliar $(\mathrm{P}=$ perenifólia; $\mathrm{S}=$ semicaducifólia; $\mathrm{D}=$ caducifólia); $\mathrm{DA}=$ densidade absoluta; $\mathrm{DR}=$ densidade relativa; $\mathrm{FA}=$ frequência absoluta; $\mathrm{FR}=$ frequência relativa; $\mathrm{ABA}=$ área basal absoluta; $\mathrm{ABR}=$ área basal relativa; $\mathrm{IVC}=$ índice de valor de cobertura; $\mathrm{NCo}=$ não coletada.

TABLE 1: Phytosociological parameters of the species sampled in a forest remnant in the municipality of São João do Oeste, Santa Catarina state, Southern Brazil. Table in decreasing order of importance value index (IVI). $\mathrm{NC}=$ collector number; $\mathrm{FF}=$ foliar phenology $(\mathrm{P}=$ evergreen; $\mathrm{S}=$ semi-deciduous; $\mathrm{D}=$ deciduous); $\mathrm{DA}=$ absolute density; $\mathrm{DR}=$ relative density; $\mathrm{FA}=$ absolute frequency; $\mathrm{FR}=$ relative frequency; $\mathrm{ABA}=$ absolute basal area; $\mathrm{ABR}=$ relative basal area; $\mathrm{IVC}=$ coverage value index $; \mathrm{NCo}=$ not collected.

\begin{tabular}{|c|c|c|c|c|c|c|c|c|c|c|}
\hline Espécie & $\mathrm{NC}$ & FF & DA & DR & FA & FR & $\mathrm{ABA}$ & $\mathrm{ABR}$ & IVI & IVC \\
\hline Sorocea bonplandii (Baill.) W.C.Burger, Lanj. \& de Boer & DG 69 & $\mathrm{P}$ & 328,43 & 22,79 & 92,16 & 10,54 & 1,430 & 4,99 & 12,77 & 13,89 \\
\hline Nectandra megapotamica (Spreng.) Mez & DG 64 & $\mathrm{P}$ & 48,04 & 3,33 & 42,16 & 4,82 & 6,514 & 22,71 & 10,29 & 13,02 \\
\hline Inga marginata Kunth & DG 60 & $\mathrm{~S}$ & 198,04 & 13,74 & 74,51 & 8,52 & 1,213 & 4,23 & 8,83 & 8,99 \\
\hline Ocotea diospyrifolia (Meisn.) Mez & DG 2 & $\mathrm{P}$ & 36,27 & 2,52 & 32,35 & 3,70 & 3,235 & 11,28 & 5,83 & 6,90 \\
\hline Trichilia claussenii C. DC. & DG 71 & $\mathrm{P}$ & 90,20 & 6,26 & 54,90 & 6,28 & 0,624 & 2,17 & 4,90 & 4,22 \\
\hline Cabralea canjerana (Vell.) Mart. & DG 21 & $\mathrm{D}$ & 62,75 & 4,35 & 46,08 & 5,27 & 1,335 & 4,66 & 4,76 & 4,50 \\
\hline Actinostemon concolor (Spreng.) Müll.Arg. & DG 48 & $\mathrm{P}$ & 96,08 & 6,67 & 28,43 & 3,25 & 0,366 & 1,28 & 3,73 & 3,97 \\
\hline Machaerium stipitatum (DC.) Vogel & DG 33 & $\mathrm{D}$ & 33,33 & 2,31 & 22,55 & 2,58 & 1,234 & 4,30 & 3,06 & 3,31 \\
\hline Calyptranthes tricona D.Legrand & DG 20 & $\mathrm{P}$ & 38,24 & 2,65 & 27,45 & 3,14 & 0,402 & 1,40 & 2,40 & 2,03 \\
\hline $\begin{array}{l}\text { Chrysophyllum gonocarpum (Mart. \& Eichler ex Miq.) } \\
\text { Engl. }\end{array}$ & DG 13 & $\mathrm{~S}$ & 26,47 & 1,84 & 22,55 & 2,58 & 0,718 & 2,50 & 2,31 & 2,17 \\
\hline Cedrela fissilis Vell. & DG 52 & $\mathrm{D}$ & 6,86 & 0,48 & 6,86 & 0,78 & 1,547 & 5,39 & 2,22 & 2,94 \\
\hline Apuleia leiocarpa (Vogel) J.F.Macbr. & DG 24 & $\mathrm{D}$ & 15,69 & 1,09 & 14,71 & 1,68 & 0,784 & 2,73 & 1,83 & 1,91 \\
\hline Allophylus edulis (A.St.-Hil., A.Juss. \& Cambess.) Radlk. & DG 15 & $\mathrm{D}$ & 16,67 & 1,16 & 16,67 & 1,91 & 0,692 & 2,41 & 1,83 & 1,79 \\
\hline Chrysophyllum marginatum (Hook. \& Arn.) Radlk. & DG 6 & $\mathrm{~S}$ & 19,61 & 1,36 & 17,65 & 2,02 & 0,342 & 1,19 & 1,52 & 1,28 \\
\hline Sebastiania brasiliensis Spreng. & DG 27 & $\mathrm{~S}$ & 22,55 & 1,56 & 16,67 & 1,91 & 0,263 & 0,92 & 1,46 & 1,24 \\
\hline Campomanesia xanthocarpa (Mart.) O.Berg & DG 12 & $\mathrm{D}$ & 21,57 & 1,50 & 19,61 & 2,24 & 0,175 & 0,61 & 1,45 & 1,05 \\
\hline Machaerium paraguariense Hassl. & DG 34 & $\mathrm{D}$ & 8,82 & 0,61 & 8,82 & 1,01 & 0,663 & 2,31 & 1,31 & 1,46 \\
\hline Syagrus romanzoffiana (Cham.) Glassman & $\mathrm{NCo}$ & $\mathrm{P}$ & 14,71 & 1,02 & 13,73 & 1,57 & 0,365 & 1,27 & 1,29 & 1,15 \\
\hline Balfourodendron riedelianum (Engl.) Engl. & DG 10 & $\mathrm{D}$ & 14,71 & 1,02 & 12,75 & 1,46 & 0,395 & 1,38 & 1,29 & 1,20 \\
\hline Guarea macrophylla Vahl & DG 57 & $\mathrm{P}$ & 20,59 & 1,43 & 18,63 & 2,13 & 0,079 & 0,27 & 1,28 & 0,85 \\
\hline Calliandra foliolosa Benth. & DG 50 & $\mathrm{D}$ & 22,55 & 1,56 & 16,67 & 1,91 & 0,092 & 0,32 & 1,26 & 0,94 \\
\hline Diatenopteryx sorbifolia Radlk. & $\mathrm{NCo}$ & $\mathrm{D}$ & 10,78 & 0,75 & 9,80 & 1,12 & 0,464 & 1,62 & 1,16 & 1,18 \\
\hline Trichilia catigua A.Juss. & DG 5 & $\mathrm{P}$ & 17,65 & 1,22 & 16,67 & 1,91 & 0,082 & 0,29 & 1,14 & 0,76 \\
\hline Prunus myrtifolia (L.) Urb. & DG 28 & $\mathrm{P}$ & 14,71 & 1,02 & 12,75 & 1,46 & 0,248 & 0,86 & 1,11 & 0,94 \\
\hline Pilocarpus pennatifolius Lem. & DG 66 & $\mathrm{P}$ & 17,65 & 1,22 & 14,71 & 1,68 & 0,090 & 0,32 & 1,07 & 0,77 \\
\hline Holocalyx balansae Micheli & DG 58 & $\mathrm{~S}$ & 5,88 & 0,41 & 5,88 & 0,67 & 0,529 & 1,85 & 0,98 & 1,13 \\
\hline Trichilia elegans A.Juss. & DG 72 & $\mathrm{P}$ & 15,69 & 1,09 & 13,73 & 1,57 & 0,036 & 0,13 & 0,93 & 0,61 \\
\hline Dalbergia frutescens (Vell.) Britton & DG 56 & $\mathrm{D}$ & 15,69 & 1,09 & 11,76 & 1,35 & 0,099 & 0,34 & 0,93 & 0,72 \\
\hline Aspidosperma australe Müll.Arg. & DG 16 & $\mathrm{D}$ & 9,80 & 0,68 & 9,80 & 1,12 & 0,268 & 0,93 & 0,91 & 0,81 \\
\hline Jacaratia spinosa (Aubl.) A.DC. & DG 61 & $\mathrm{D}$ & 5,88 & 0,41 & 4,90 & 0,56 & 0,500 & 1,74 & 0,90 & 1,08 \\
\hline Styrax leprosus Hook. \& Arn. & DG 9 & $\mathrm{P}$ & 8,82 & 0,61 & 6,86 & 0,78 & 0,366 & 1,28 & 0,89 & 0,94 \\
\hline Pisonia ambigua Heimerl & DG 3 & $\mathrm{~S}$ & 6,86 & 0,48 & 6,86 & 0,78 & 0,299 & 1,04 & 0,77 & 0,76 \\
\hline Urera baccifera (L.) Gaudich. & DG 73 & $\mathrm{D}$ & 12,75 & 0,88 & 9,80 & 1,12 & 0,085 & 0,30 & 0,77 & 0,59 \\
\hline Annona neosalicifolia H.Rainer & DG 29 & $\mathrm{D}$ & 7,84 & 0,54 & 6,86 & 0,78 & 0,232 & 0,81 & 0,71 & 0,68 \\
\hline
\end{tabular}


TABELA 1: Continuação...

TABLE 1: Continued...

\begin{tabular}{|c|c|c|c|c|c|c|c|c|c|c|}
\hline Espécie & $\mathrm{NC}$ & $\mathrm{FF}$ & $\mathrm{DA}$ & DR & FA & FR & $\mathrm{ABA}$ & $\mathrm{ABR}$ & IVI & IVC \\
\hline Casearia sylvestris $\mathrm{Sw}$. & DG 23 & $\mathrm{P}$ & 7,84 & 0,54 & 7,84 & 0,90 & 0,190 & 0,66 & 0,70 & 0,60 \\
\hline Nectandra lanceolata Nees \& Mart. & DG 63 & $\mathrm{~S}$ & 1,96 & 0,14 & 1,96 & 0,22 & 0,470 & 1,64 & 0,67 & 0,89 \\
\hline Myrocarpus frondosus Allemão & DG 35 & $\mathrm{D}$ & 8,82 & 0,61 & 7,84 & 0,90 & 0,128 & 0,45 & 0,65 & 0,53 \\
\hline Trema micrantha $(\mathrm{L}$.$) Blume$ & DG 70 & $\mathrm{~S}$ & 11,76 & 0,82 & 6,86 & 0,78 & 0,039 & 0,13 & 0,58 & 0,48 \\
\hline Cupania vernalis Cambess. & DG 55 & $\mathrm{~S}$ & 6,86 & 0,48 & 5,88 & 0,67 & 0,130 & 0,45 & 0,53 & 0,46 \\
\hline Eugenia burkartiana (D.Legrand) D.Legrand & DG 22 & $\mathrm{P}$ & 7,84 & 0,54 & 7,84 & 0,90 & 0,040 & 0,14 & 0,53 & 0,34 \\
\hline Casearia decandra Jacq. & DG 25 & $\mathrm{D}$ & 7,84 & 0,54 & 4,90 & 0,56 & 0,108 & 0,38 & 0,49 & 0,46 \\
\hline Seguieria americana $\mathrm{L}$. & DG 68 & $\mathrm{~S}$ & 6,86 & 0,48 & 6,86 & 0,78 & 0,060 & 0,21 & 0,49 & 0,34 \\
\hline Picrasma crenata Engl. in Engl. \& Prantl & DG 39 & $\mathrm{D}$ & 5,88 & 0,41 & 5,88 & 0,67 & 0,102 & 0,36 & 0,48 & 0,38 \\
\hline Bauhinia forficata Link & DG 19 & $\mathrm{D}$ & 6,86 & 0,48 & 6,86 & 0,78 & 0,038 & 0,13 & 0,46 & 0,30 \\
\hline Schefflera morototoni (Aubl.) Maguire, Steyerm. \& Frodin & DG 67 & $\mathrm{P}$ & 4,90 & 0,34 & 4,90 & 0,56 & 0,091 & 0,32 & 0,41 & 0,33 \\
\hline Luehea divaricata Mart. & DG 4 & $\mathrm{D}$ & 1,96 & 0,14 & 1,96 & 0,22 & 0,240 & 0,84 & 0,40 & 0,49 \\
\hline Cordia trichotoma (Vell.) Arráb. ex Steud. & DG 32 & $\mathrm{D}$ & 4,90 & 0,34 & 4,90 & 0,56 & 0,081 & 0,28 & 0,39 & 0,31 \\
\hline Matayba elaeagnoides Radlk. & DG 62 & $\mathrm{~S}$ & 3,92 & 0,27 & 3,92 & 0,45 & 0,120 & 0,42 & 0,38 & 0,35 \\
\hline Cordia ecalyculata Vell. & DG 8 & $\mathrm{P}$ & 3,92 & 0,27 & 2,94 & 0,34 & 0,135 & 0,47 & 0,36 & 0,37 \\
\hline Gleditsia amorphoides (Griseb.) Taub. & DG 30 & $\mathrm{D}$ & 1,96 & 0,14 & 1,96 & 0,22 & 0,182 & 0,63 & 0,33 & 0,39 \\
\hline Citronella paniculata (Mart.) R.A.Howard & DG 7 & $\mathrm{P}$ & 3,92 & 0,27 & 3,92 & 0,45 & 0,042 & 0,15 & 0,29 & 0,21 \\
\hline Banara tomentosa $\mathrm{Clos}$ & DG 14 & $\mathrm{D}$ & 2,94 & 0,20 & 2,94 & 0,34 & 0,080 & 0,28 & 0,27 & 0,24 \\
\hline Campomanesia guazumifolia (Cambess.) O.Berg & DG 51 & $\mathrm{D}$ & 3,92 & 0,27 & 3,92 & 0,45 & 0,018 & 0,06 & 0,26 & 0,17 \\
\hline Hennecartia omphalandra Poiss. & DG 18 & $\mathrm{P}$ & 3,92 & 0,27 & 3,92 & 0,45 & 0,017 & 0,06 & 0,26 & 0,17 \\
\hline Annona rugulosa (Schltdl.) H.Rainer & DG 41 & $\mathrm{D}$ & 3,92 & 0,27 & 3,92 & 0,45 & 0,016 & 0,06 & 0,26 & 0,16 \\
\hline Indeterminadas & $\mathrm{NCo}$ & - & 2,94 & 0,20 & 2,94 & 0,34 & 0,061 & 0,21 & 0,25 & 0,21 \\
\hline Eugenia uniflora L. & $\mathrm{NCo}$ & $\mathrm{S}$ & 2,94 & 0,20 & 2,94 & 0,34 & 0,040 & 0,14 & 0,23 & 0,17 \\
\hline Strychnos brasiliensis (Spreng.) Mart. & DG 36 & $\mathrm{D}$ & 2,94 & 0,20 & 2,94 & 0,34 & 0,033 & 0,12 & 0,22 & 0,16 \\
\hline Ocotea puberula (Rich.) Nees & DG 65 & $\mathrm{~S}$ & 0,98 & 0,07 & 0,98 & 0,11 & 0,132 & 0,46 & 0,21 & 0,26 \\
\hline Parapiptadenia rigida (Benth.) Brenan & $\mathrm{NCo}$ & $\mathrm{D}$ & 2,94 & 0,20 & 2,94 & 0,34 & 0,016 & 0,06 & 0,20 & 0,13 \\
\hline Ruprechtia laxiflora Meisn. & DG 42 & $\mathrm{D}$ & 1,96 & 0,14 & 1,96 & 0,22 & 0,022 & 0,08 & 0,15 & 0,11 \\
\hline Jacaranda micrantha Cham. & DG 31 & $\mathrm{D}$ & 0,98 & 0,07 & 0,98 & 0,11 & 0,073 & 0,25 & 0,14 & 0,16 \\
\hline Eugenia involucrata DC. & DG 11 & $\mathrm{D}$ & 1,96 & 0,14 & 1,96 & 0,22 & 0,013 & 0,04 & 0,13 & 0,09 \\
\hline Cordia americana (L.) Gottschling \& J.S.Mill. & DG 54 & $\mathrm{D}$ & 1,96 & 0,14 & 1,96 & 0,22 & 0,012 & 0,04 & 0,13 & 0,09 \\
\hline Myrsine balansae (Mez) Otegui & DG 26 & $\mathrm{P}$ & 1,96 & 0,14 & 1,96 & 0,22 & 0,011 & 0,04 & 0,13 & 0,09 \\
\hline Eugenia pyriformis Cambess. & DG 1 & $\mathrm{~S}$ & 0,98 & 0,07 & 0,98 & 0,11 & 0,049 & 0,17 & 0,12 & 0,12 \\
\hline Erythrina falcata Benth. & DG 44 & $\mathrm{D}$ & 0,98 & 0,07 & 0,98 & 0,11 & 0,030 & 0,10 & 0,09 & 0,09 \\
\hline Casearia obliqua Spreng. & DG 40 & $\mathrm{D}$ & 0,98 & 0,07 & 0,98 & 0,11 & 0,018 & 0,06 & 0,08 & 0,06 \\
\hline Celtis iguanaea (Jacq.) Sarg. & DG 53 & $\mathrm{~S}$ & 0,98 & 0,07 & 0,98 & 0,11 & 0,017 & 0,06 & 0,08 & 0,06 \\
\hline Sebastiania commersoniana (Baill.) L.B.Sm. \& Downs & DG 46 & $\mathrm{D}$ & 0,98 & 0,07 & 0,98 & 0,11 & 0,012 & 0,04 & 0,07 & 0,05 \\
\hline Vitex megapotamica (Spreng.) Moldenke & DG 74 & $\mathrm{D}$ & 0,98 & 0,07 & 0,98 & 0,11 & 0,010 & 0,04 & 0,07 & 0,05 \\
\hline Diospyros inconstans Jacq. & DG 75 & $\mathrm{P}$ & 0,98 & 0,07 & 0,98 & 0,11 & 0,008 & 0,03 & 0,07 & 0,05 \\
\hline Zanthoxylum petiolare A.St.-Hil. \& Tul. & DG 45 & $\mathrm{D}$ & 0,98 & 0,07 & 0,98 & 0,11 & 0,006 & 0,02 & 0,07 & 0,04 \\
\hline Myrsine loefgrenii (Mez) Imkhan. & DG 47 & $\mathrm{P}$ & 0,98 & 0,07 & 0,98 & 0,11 & 0,005 & 0,02 & 0,07 & 0,04 \\
\hline Boehmeria caudata Sw. & DG 49 & $\mathrm{~S}$ & 0,98 & 0,07 & 0,98 & 0,11 & 0,004 & 0,01 & 0,06 & 0,04 \\
\hline Lonchocarpus campestris Benth. & DG 17 & $\mathrm{D}$ & 0,98 & 0,07 & 0,98 & 0,11 & 0,004 & 0,01 & 0,06 & 0,04 \\
\hline Eugenia hiemalis Cambress. & DG 37 & $\mathrm{P}$ & 0,98 & 0,07 & 0,98 & 0,11 & 0,004 & 0,01 & 0,06 & 0,04 \\
\hline Heliocarpus americanus $\mathrm{L}$. & DG 38 & $\mathrm{~S}$ & 0,98 & 0,07 & 0,98 & 0,11 & 0,002 & 0,01 & 0,06 & 0,04 \\
\hline Dahlstedtia pinnata (Benth.) Malme & DG 43 & $\mathrm{P}$ & 0,98 & 0,07 & 0,98 & 0,11 & 0,002 & 0,01 & 0,06 & 0,04 \\
\hline Hovenia dulcis Thunb. (espécie exótica para o Brasil) & DG 59 & $\mathrm{D}$ & 0,98 & 0,07 & 0,98 & 0,11 & 0,002 & 0,01 & 0,06 & 0,04 \\
\hline
\end{tabular}




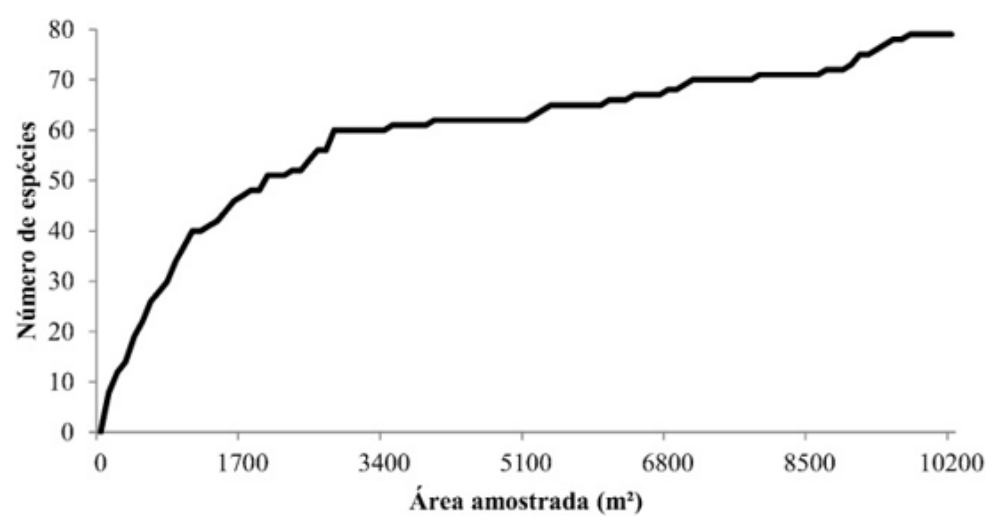

FIGURA 2: Curva espécies/área de um remanescente florestal no município de São João do Oeste - SC. FIGURE 2: Species/area curve of a forest remnant in the municipality of São João do Oeste, Santa Catarina state, southern Brazil.

espécies dominam o estrato das arvoretas na FED de Santa Catarina, porém, em diferentes condições edáficas locais. Klein (1978) enfatizou o predomínio, abundância e frequência das espécies Sorocea bonplandii e Actinostemon concolor na FED do estado. Estas, junto à Trichilia claussenii, de acordo com Reitz et al. (1988), são responsáveis pela homogeneidade fitofisionômica do estrato das arvoretas na vegetação da Bacia do Alto Rio Uruguai, constituindo cerca de 40 a $70 \%$ das plantas, embora tenham totalizado 35,71\% no presente estudo, possivelmente em função da grande quantidade de plantas de Inga marginata.

Além de Trichilia claussenii, as espécies Trichilia catigua e Trichilia elegans também são abundantes na FED (MARCHIORI, 2000). Embora a última espécie tenha apresentado a menor densidade dentre as três, a mesma é sem dúvida a mais abundante das Trichilia na área amostrada, não tendo tido maior expressão nos resultados em função do critério de inclusão adotado.

A abundância de Sorocea bonplandii no presente estudo foi a mais alta em relação a inventários realizados no sul do Brasil, embora seja uma das espécies mais abundantes na FED (KLEIN, 1978) e tenha também apresentado alta abundância em outros trabalhos (e.g., 202 plantas/ha em RUSCHEL et al., 2009; e 255 plantas/ha em JARENKOW; WAECHTER, 2001).

Ao contrário de Sorocea bonplandii, Actinostemon concolor apresentou abundância relativamente baixa em relação a outros estudos (e.g., 240 plantas/ha em SCIPIONI et al., 2011; 632 plantas/ha em JARENKOW; WAECHTER, 2001; 715 plantas/ha em BUDKE et al., 2004). Do total de plantas amostradas, $87,8 \%$ ficou restrita a apenas $30,77 \%$ das parcelas em um dos extremos da amostra. Giehl et al. (2007) supuseram que a distribuição espacial agrupada da espécie possa se dever ao mecanismo de dispersão autocórico de diásporos, a uma possível tolerância à competição intraespecífica e ao poder competitivo interespecífico durante o estabelecimento inicial, o que pode explicar a abundância local e, em parte, a distribuição espacial restrita na área amostrada.

Embora Inga marginata não tenha sido descrita por Burkart (1979) como fitossociologicamente importante em florestas conservadas no estado, tida como ocorrendo preferencialmente em capoeiras de solos úmidos, beira de rios e regatos (REITZ et al., 1978; MARCHIORI, 1997), no presente estudo e no de Giehl e Jarenkow (2008), realizados em áreas geograficamente próximas, a espécie apresentou a segunda e a terceira maior abundância, respectivamente. Apesar de o estudo dos últimos autores ter sido realizado em uma floresta ribeirinha, a espécie apresentou maior frequência nas áreas mais elevadas.

Mesmo com apenas 87,25 plantas/ha, a família Lauraceae apresentou a maior ABA, seguida de Fabaceae, Meliaceae e Moraceae (Tabela 2). As espécies com as maiores áreas basais foram Nectandra megapotamica, Ocotea diospyrifolia, Cedrela fissilis e Sorocea bonplandii.

As Lauraceae Nectandra lanceolata, Nectandra megapotamica, Ocotea diospyrifolia e Ocotea puberula, juntamente com a Boraginaceae Cordia americana, foram citadas por Leite (2002) como algumas das espécies "perenifólias" mais importantes para a fisionomia da FED no período desfavorável. 
De acordo com Pedralli (1987) e Reitz et al. (1988), Nectandra megapotamica se torna frequentemente a macrofanerófita dominante, o que foi observado no presente estudo, resultando, junto a outras espécies da família, em uma fácies de bosque de lauráceas na época hibernal, quando revelam sua densa e uniforme cobertura após a queda das folhas da maioria das árvores emergentes (KLEIN, 1978; 1984a).

Os maiores valores de IVI e IVC foram das duas espécies com as maiores áreas basais, Nectandra megapotamica e Ocotea diospyrifolia, e com as duas maiores densidades e frequências, Sorocea bonplandii e Inga marginata, somando estas $12,57 \%$ e $14,26 \%$ do total dos parâmetros nesta ordem. Vários estudos nos estados sulinos brasileiros têm mostrado espécies de arvoretas figurando com altos valores de IVI principalmente (e.g., JARENKOW; WAECHTER, 2001; SCIPIONI et al., 2011), já que o IVC tem sido pouco usado, embora forneça informações importantes e não seja influenciado pelo tamanho da unidade amostral (DURIGAN, 2006), que varia em alguns trabalhos.

Em relação à estrutura vertical, optou-se por sugerir a distribuição das árvores em três intervalos de altura (Figura 3), correspondentes ao extrato das arvoretas $(2-11 \mathrm{~m})$, ao dossel $(12-17 \mathrm{~m})$ e às árvores emergentes (18-25 m). O número de estratos propostos é reiterado pela descrição da estrutura vertical da FED/SC feita por Klein (1978), que adiciona ainda o das plantas arbustivas.

As espécies com as maiores densidades nos estratos foram: Sorocea bonplandii (160 plantas com alturas mensuradas/1,02 ha), Inga marginata (102), Trichilia claussenii, Actinostemon concolor (46) e Cabralea canjerana (31) no estrato das arvoretas (que apresentou 60 espécies, 591 plantas e 3,37 $\mathrm{m}^{2}$ de ABA/1,02 ha); Inga marginata (13), Syagrus romanzoffiana (12), Cabralea canjerana, Nectandra megapotamica (9) e Ocotea diospyrifolia (7) no dossel (36 espécies, 132 plantas e 6,18 $\mathrm{m}^{2}$ de ABA) e Nectandra megapotamica (8), Apuleia leiocarpa, Machaerium stipitatum (5), Ocotea diospyrifolia (4) e Cedrela fissilis (3) no grupo das árvores emergentes (11 espécies, 32 plantas e 6,56 $\mathrm{m}^{2}$ de ABA).

Na Figura 3, pode-se observar que tende a haver uma redução da riqueza, abundância e área basal de plantas perenifólias e semidecíduas de posições inferiores às superiores na estrutura vertical e, em contrapartida, um aumento desses valores associados às plantas decíduas, embora ocorram algumas variações.

Grande parte da literatura que classifica a Floresta Estacional Decidual como a formação florestal na qual mais de $50 \%$ dos meso e macrofanerófitos perdem as folhas na estação desfavorável, não versa sobre a contabilização ou não de plantas de espécies semidecíduas para a definição da deciduidade (VELOSO et al., 1991; IBGE, 2012; LEITE, 2002). Já Klein (1978) classifica como decíduas as plantas que perdem total ou parcialmente suas folhas no inverno. Quando consideradas apenas as plantas decíduas, tanto as do estrato superior como exclusivamente os meso e macrofanerófitos, a vegetação não mantém o status de decidual ( $50 \%$ de plantas decíduas em ambos os casos), ao contrário do que ocorre quando as plantas semidecíduas são contabilizadas $(59,4 \%)$. Além do exposto, a subjetividade inerente à determinação de estratos está diretamente vinculada às proporções resultantes.

$\mathrm{O}$ estrato das arvoretas apresentou a maior riqueza, o que se deve à ocorrência de regenerantes de plantas que aparecem também nos estratos superiores (DURIGAN, 2012). Essa característica é evidenciada pela amplitude das alturas e de diâmetros a altura do peito de algumas espécies que atingem grande porte (Figura 4 A e B), e também pela quantidade de espécies decíduas ocupando o estrato inferior. Das 26 espécies decíduas com até 11 metros de altura, 14 também ocorreram no dossel ou como emergentes.

De acordo com Klein (1984a), a cobertura superior descontínua da FED/SC, formada pelas árvores emergentes, ostenta árvores que chegam a atingir de 30 a 40 metros de altura, com destaque para as espécies decíduas Parapiptadenia rigida, Balfourodendron riedelianum, Cedrela fissilis, Apuleia leiocarpa e Myrocarpus frondosus. O fato de poucas plantas de grande porte terem sido amostradas pode ter determinado a relativa baixa porcentagem de deciduidade do componente emergente. Essa constatação sugere a influência de fatores como o efeito de borda na redução da quantidade dessas plantas, já que a vegetação adjacente à área amostral foi explorada há algumas décadas, o que possibilita o aumento da turbulência de ventos (LAURANCE, 1997; DELAMÔNICA et al., 2001), resultando em uma taxa elevada de quedas e de danos às árvores (WILLIAMS-LINERA, 1990; FERREIRA; LAURANCE, 1997; LAURANCE et al., 1998; 2000). Como consequência desse provável efeito, das 1.470 plantas amostradas, apenas $755(51,36 \%)$ tiveram suas alturas mensuradas, o que é um reflexo da condição física das mesmas.

$\mathrm{O}$ efeito de borda, somado à dificuldade da mensuração das alturas das plantas, que é bastante 
TABELA 2: Parâmetros fitossociológicos das famílias amostradas em um remanescente florestal no município de São João do Oeste - SC, em ordem decrescente de índice de valor de importância (IVI). $\mathrm{S}=$ Riqueza; $\mathrm{DA}=$ densidade absoluta; $\mathrm{DR}=$ densidade relativa; $\mathrm{FA}=$ frequência absoluta; $\mathrm{FR}$ = frequência relativa; $\mathrm{ABA}$ = área basal absoluta; $\mathrm{ABR}$ = área basal relativa; $\mathrm{IVC}=$ índice de valor de cobertura.

TABLE 2: Phytosociological parameters of the families sampled in a forest remnant in the municipality of São João do Oeste, Santa Catarina state, southern Brazil, in decreasing order of importance value index (IVI). $\mathrm{S}=$ richness; $\mathrm{DA}=$ absolute density; $\mathrm{DR}=$ relative density; FA = absolute frequency; $\mathrm{FR}=$ relative frequency; $\mathrm{ABA}=$ absolute basal area; $\mathrm{ABR}=$ relative basal area; $\mathrm{IVC}=$ coverage value index.

\begin{tabular}{|c|c|c|c|c|c|c|c|c|c|}
\hline Família & $\mathrm{S}$ & $\mathrm{DA}$ & $\mathrm{DR}$ & FA & FR & $\mathrm{ABA}$ & ABR & IVI & IVC \\
\hline Fabaceae & 14 & 323,53 & 22,45 & 94,12 & 13,83 & 5,015 & 17,49 & 17,92 & 19,97 \\
\hline Lauraceae & 4 & 87,25 & 6,05 & 61,76 & 9,08 & 10,352 & 36,09 & 17,07 & 21,07 \\
\hline Moraceae & 1 & 328,43 & 22,79 & 92,16 & 13,54 & 1,430 & 4,99 & 13,77 & 13,89 \\
\hline Meliaceae & 6 & 213,73 & 14,83 & 88,24 & 12,97 & 3,703 & 12,91 & 13,57 & 13,87 \\
\hline Euphorbiaceae & 3 & 119,61 & 8,30 & 41,18 & 6,05 & 0,641 & 2,23 & 5,53 & 5,27 \\
\hline Myrtaceae & 8 & 78,43 & 5,44 & 53,92 & 7,93 & 0,740 & 2,58 & 5,32 & 4,01 \\
\hline Sapindaceae & 4 & 38,24 & 2,65 & 34,31 & 5,04 & 1,406 & 4,90 & 4,20 & 3,78 \\
\hline Sapotaceae & 2 & 46,08 & 3,20 & 35,29 & 5,19 & 1,061 & 3,70 & 4,03 & 3,45 \\
\hline Rutaceae & 3 & 33,33 & 2,31 & 26,47 & 3,89 & 0,492 & 1,72 & 2,64 & 2,01 \\
\hline Salicaceae & 4 & 19,61 & 1,36 & 15,69 & 2,31 & 0,395 & 1,38 & 1,68 & 1,37 \\
\hline Arecaceae & 1 & 14,71 & 1,02 & 13,73 & 2,02 & 0,365 & 1,27 & 1,44 & 1,15 \\
\hline Rosaceae & 1 & 14,71 & 1,02 & 12,75 & 1,87 & 0,248 & 0,86 & 1,25 & 0,94 \\
\hline Annonaceae & 2 & 11,76 & 0,82 & 10,78 & 1,59 & 0,249 & 0,87 & 1,09 & 0,84 \\
\hline Apocynaceae & 1 & 9,80 & 0,68 & 9,80 & 1,44 & 0,268 & 0,93 & 1,02 & 0,81 \\
\hline Boraginaceae & 3 & 10,78 & 0,75 & 9,80 & 1,44 & 0,228 & 0,80 & 0,99 & 0,77 \\
\hline Styracaceae & 1 & 8,82 & 0,61 & 6,86 & 1,01 & 0,366 & 1,28 & 0,97 & 0,94 \\
\hline Caricaceae & 1 & 5,88 & 0,41 & 4,90 & 0,72 & 0,500 & 1,74 & 0,96 & 1,08 \\
\hline Urticaceae & 2 & 13,73 & 0,95 & 10,78 & 1,59 & 0,089 & 0,31 & 0,95 & 0,63 \\
\hline Nyctaginaceae & 1 & 6,86 & 0,48 & 6,86 & 1,01 & 0,299 & 1,04 & 0,84 & 0,76 \\
\hline Cannabaceae & 2 & 12,75 & 0,88 & 7,84 & 1,15 & 0,056 & 0,19 & 0,74 & 0,54 \\
\hline Phytolaccaceae & 1 & 6,86 & 0,48 & 6,86 & 1,01 & 0,060 & 0,21 & 0,56 & 0,34 \\
\hline Simaroubaceae & 1 & 5,88 & 0,41 & 5,88 & 0,86 & 0,102 & 0,36 & 0,54 & 0,38 \\
\hline Malvaceae & 2 & 2,94 & 0,20 & 2,94 & 0,43 & 0,241 & 0,84 & 0,49 & 0,52 \\
\hline Araliaceae & 1 & 4,90 & 0,34 & 4,90 & 0,72 & 0,091 & 0,32 & 0,46 & 0,33 \\
\hline Cardiopteridaceae & 1 & 3,92 & 0,27 & 3,92 & 0,58 & 0,042 & 0,15 & 0,33 & 0,21 \\
\hline Monimiaceae & 1 & 3,92 & 0,27 & 3,92 & 0,58 & 0,017 & 0,06 & 0,30 & 0,17 \\
\hline Indeterminadas & - & 2,94 & 0,20 & 2,94 & 0,43 & 0,061 & 0,21 & 0,28 & 0,21 \\
\hline Loganiaceae & 1 & 2,94 & 0,20 & 2,94 & 0,43 & 0,033 & 0,12 & 0,25 & 0,16 \\
\hline Primulaceae & 2 & 2,94 & 0,20 & 2,94 & 0,43 & 0,016 & 0,05 & 0,23 & 0,13 \\
\hline Polygonaceae & 1 & 1,96 & 0,14 & 1,96 & 0,29 & 0,022 & 0,08 & 0,17 & 0,11 \\
\hline Bignoniaceae & 1 & 0,98 & 0,07 & 0,98 & 0,14 & 0,073 & 0,25 & 0,16 & 0,16 \\
\hline Lamiaceae & 1 & 0,98 & 0,07 & 0,98 & 0,14 & 0,010 & 0,04 & 0,08 & 0,05 \\
\hline Ebenaceae & 1 & 0,98 & 0,07 & 0,98 & 0,14 & 0,008 & 0,03 & 0,08 & 0,05 \\
\hline Rhamnaceae & 1 & 0,98 & 0,07 & 0,98 & 0,14 & 0,002 & 0,01 & 0,07 & 0,04 \\
\hline
\end{tabular}




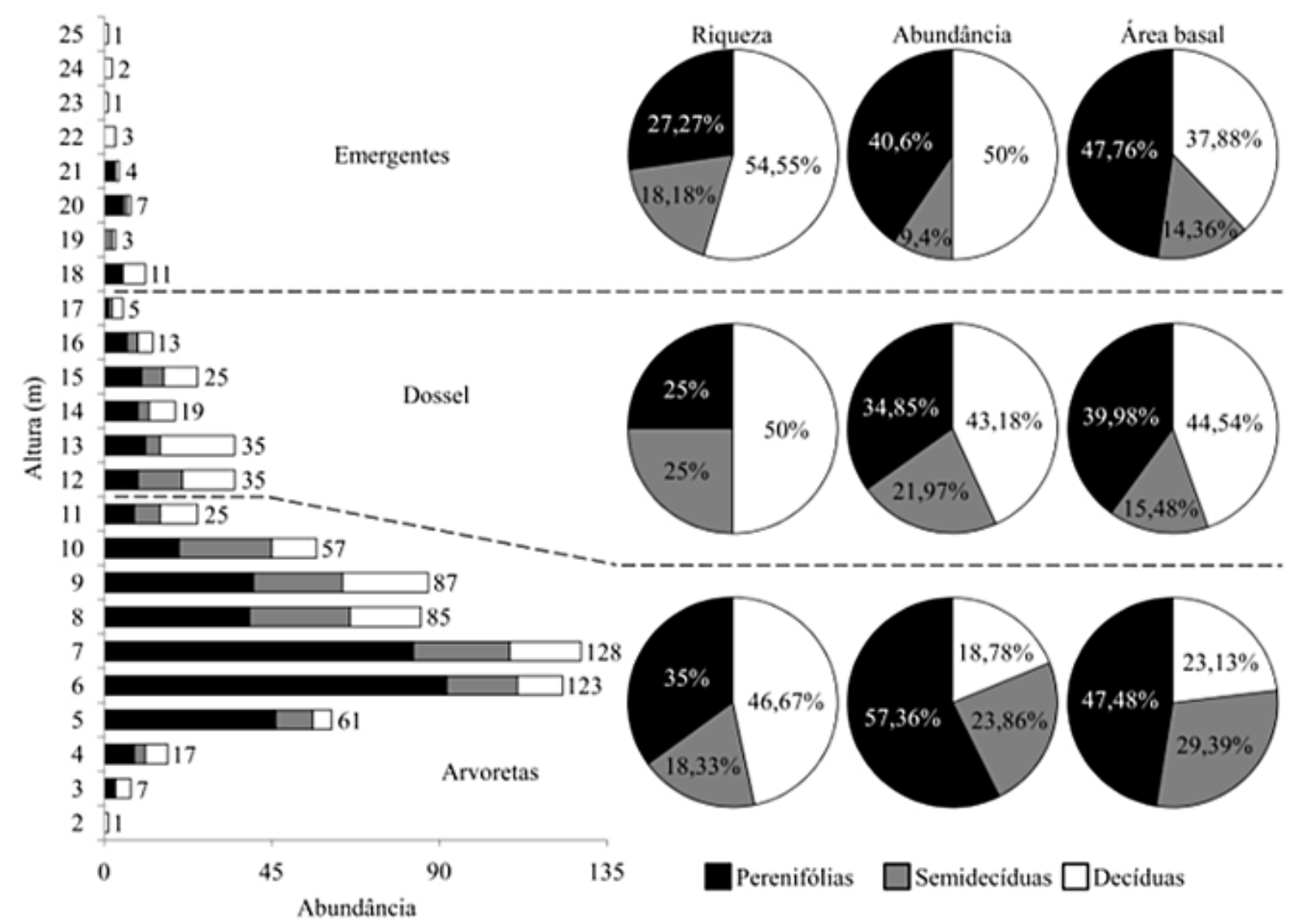

FIGURA 3: Distribuição das frequências de altura na estrutura vertical de um remanescente florestal no município de São João do Oeste - SC, proporções relativas de riqueza, abundância e área basal de plantas perenifólias, semidecíduas e decíduas, relacionadas às arvoretas, ao dossel e às árvores emergentes.

FIGURE 3: Distribution of height frequencies in the vertical structure of a forest remnant in the municipality of São João do Oeste, Santa Catarina state, relative proportions of richness, abundance and basal area of perennial, semi-deciduous and deciduous plants, related to treelets, canopy and emerging trees.

imprecisa no interior das florestas (CHAPMAN; MEYER, 1949; BRUCE; SCHUMACHER, 1950), podem ter sido as influências mais importantes nas proporções relativas de fenologia foliar da estrutura vertical da floresta, já que possuem influência direta sobre a delimitação dos estratos. Além de ser difícil (LAMPRECHT, 1964; DURIGAN et al., 2000; SANQUETTA et al., 2001; JARENKOW; BUDKE, 2009), ainda não há um método estabelecido para a definição da estratificação de florestas tropicais (DURIGAN, 2012), sendo as tentativas consideradas arbitrárias por alguns autores (GRUBB et al., 1963; HALLÉ et al., 1978; RICHARDS, 1996).

Embora a delimitação do estrato das arvoretas tenha sido relativamente fácil, o mesmo não é válido para a separação do dossel das árvores emergentes, o que se deve à existência de vários picos de frequências de altura acima dos 11 metros. Tal característica pode advir do fato de que existem árvores emergentes jovens ocupando o dossel (BROWN, 1919; DURIGAN, 2012), e que ainda não atingiram suas alturas finais (GRUBB et al., 1963), bem como a uma série de fatores já comentados.

A falta de inventários fitossociológicos com amostragem mínima de um hectare na FED da região dificulta as análises sobre estratificação. 

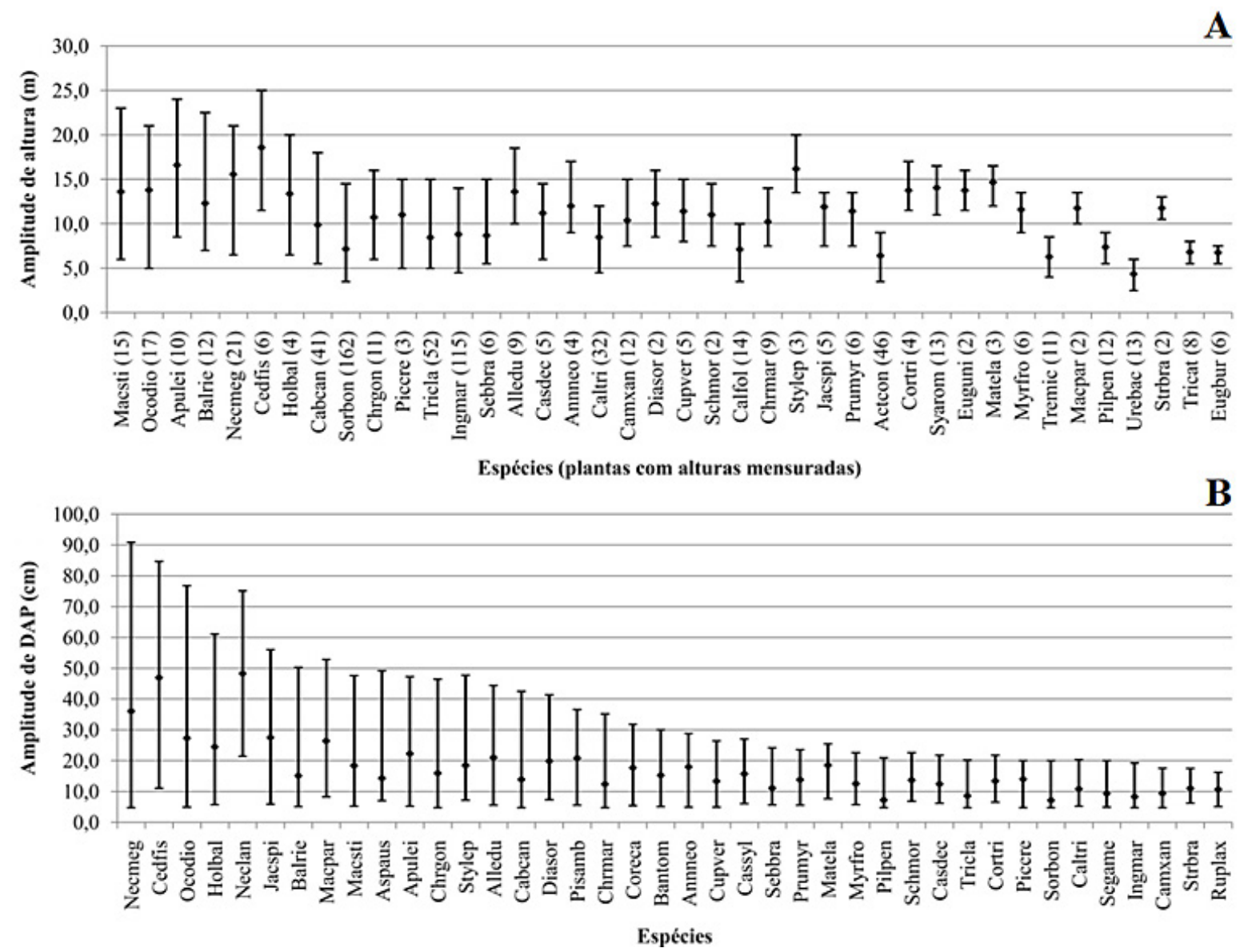

FIGURA 4: Amplitudes de altura (A) e de diâmetro à altura do peito (B) de algumas espécies, em ordem decrescente de amplitudes. Os nomes das espécies estão representados pelas três primeiras letras dos epítetos genérico e específico.

FIGURE 4: Height (A) and diameter at breast height (B) amplitudes of some species, in decreasing order of amplitudes. The names of the species are represented by the first three letters of the generic and specific epithets.

\section{CONCLUSÕES}

O remanescente florestal estudado apresenta características florístico-estruturais condizentes com as encontradas na literatura sobre as florestas primárias da região, sendo que constitui um importante ecossistema de referência para futuras estratégias de preservação, manejo e restauração dessas florestas.

\section{AGRADECIMENTOS}

Ao Renato Aquino Záchia, Maria de Fátima Freitas, Efigênia de Melo, José Rubens Pirani e Marcos Eduardo Guerra Sobral pela identificação de espécies de Annonaceae, Primulaceae, Polygonaceae, Rutaceae e Ebenaceae e Myrtaceae, respectivamente; ao Walter Hammes, pela concessão do acesso à área de estudo; e à SED-SC - Art. 170/CE-SC, pelas bolsas de iniciação científica concedidas aos dois primeiros autores.

\section{REFERÊNCIAS}

ALVARES, C. A. et al. Köppen's climate classification map for Brazil. Meteorologische Zeitschrift, 
Berlin, v. 22, n. 6, p. 711-728, 2014.

ANGIOSPERM PHYLOGENY GROUP. An update of the Angiosperm Phylogeny Group classification for the orders and families of flowering plants: APG III. Botanical Journal of the Linnean Society, London, v. 161, p. 105-121, 2009.

ARONSON, J.; DHILLION, S.; LE FLOC'H., E. On the need to select on ecosystem of reference, however imperfect: a reply to Pickett e Parker. Restoration Ecology, Malden, v. 3, n. 1, p. 1-3, 1995.

ATHAYDE, E. A. et al. Fenologia de espécies arbóreas em uma floresta ribeirinha em Santa Maria, sul do Brasil. Revista Brasileira de Biociências, Porto Alegre, v. 7, n. 1, p. 43-51, 2009.

BROWER, J. E.; ZAR, J. H. Field and laboratory methods for general ecology. Duduque: W.M.C. Brow Publishers, 1984. 84 p.

BROWN, W. H. Vegetation of the Philippine Mountains: the relation between the environment and physical types at different altitudes. Manila: Bureau of Science, 1919. $434 \mathrm{p}$.

BRUCE, D.; SCHUMACHER, F. X. Forest mensuration. New York: McGraw-Hill, 1950. 483 p.

BUDKE, J. C. et al. Florística e fitossociologia do componente arbóreo de uma floresta ribeirinha, arroio Passo das Tropas, Santa Maria, RS, Brasil. Acta Botanica Brasilica, Belo Horizonte, v. 18, n. 3, p. 581-589, 2004.

BUDKE, J. C.; JARENKOW, J. A.; OLIVEIRA-FILHO, A. T. Relationships between tree component structure, topography and soil of a riverside forest, rio Botucaraí, southern Brazil. Plant Ecology, Dordrecht, v. 189, n. 2, p. 187-200, 2007.

BURKART, A. Leguminosas. In: REITZ, R. (Ed.). Flora Ilustrada Catarinense. Itajaí: Herbário Barbosa Rodrigues, 1979. 299 p.

CHAPMAN, H. H.; MEYER, W. H. Forest mensuration. New York: McGraw-Hill, 1949. 522 p.

CENTRO NACIONAL DE CONSERVAÇÃO DA FLORA. Centro Nacional de Conservação da Flora.

2013. Disponível em: <http://cncflora.jbrj.gov.br/portal/>. Acesso em: 11 jun. 2015.

DELAMÔNICA, P.; LAURANCE, W. F.; LAURANCE, S. G. A fragmentação da paisagem. In: VARELLA, D. (Coord.). Florestas do Rio Negro. São Paulo: Companhia das Letras, UNIP, 2001. p. 283-301.

DURIGAN, G. Métodos para análise de vegetação arbórea. In: CULLEN JUNIOR, L.; RUDRAN, R.; VALLADARES-PADUA, C. (Orgs.). Métodos de estudos em biologia da conservação e manejo da vida silvestre. Curitiba: Editora UFPR, 2006. p. 455-479.

DURIGAN, G. Estrutura e diversidade de comunidades florestais. In: MARTINS, S. V. (Ed.). Ecologia de florestas tropicais do Brasil. Viçosa: Editora UFV, 2012. p. 294-325.

DURIGAN, G. et al. Estrutura e diversidade do componente arbóreo da floresta na Estação Ecológica dos Caetetus, Gália, SP. Revista Brasileira de Botânica, São Paulo, v. 23, n. 4, p. 371-383, 2000.

DURIGAN, G.; RODRIGUES, R. R.; SCHIAVINI, I. A heterogeneidade ambiental definindo a metodologia de amostragem da floresta ciliar. In: RODRIGUES, R. R.; LEITÃO-FILHO, H. F. (Eds.). Matas ciliares: conservação e recuperação. São Paulo: Edusp; Fapesp, 2001. p. 159-167.

FELFILI, J. M. et al. Procedimentos e métodos de amostragem de vegetação. In:

Fitossociologia no Brasil: métodos e estudos de caso. Viçosa: Editora UFV, 2011. p. 86-121.

FELFILI, J. M.; CARVALHO, F. A.; HAIDAR, R. F. Manual para o monitoramento de parcelas permanentes nos biomas Cerrado e Pantanal. Brazília: Editora UnB, 2005. 51 p.

FERREIRA, L. V.; LAURANCE, W. F. Effects of forest fragmentation on mortality and damage of selected tree in central Amazonia. Conservation Biology, Boston, v. 20, p. 243-246, 1997.

GIEHL, E. L. H. et al. Espectro e distribuição vertical das estratégias de dispersão de diásporos do componente arbóreo em uma floresta estacional no sul do Brasil. Acta Botanica Brasilica, Belo Horizonte, v. 21, n. 1, p. 137-145, 2007.

GIEHL, E. L. H.; JARENKOW, J. A. Gradiente estrutural do componente arbóreo e relação com inundações em uma floresta ribeirinha, rio Uruguai, sul do Brasil. Acta Botanica Brasilica, Belo Horizonte, v. 22, n. 3, p. 741-753, 2008.

GRUBB, P. J. et al. A comparison of montane and lowland rain forest in Ecuador. I. The forest structure, physiognomy, and floristics. Journal of Ecology, Oxford, v. 51, n. 3, p. 567-601, 1963.

GUREVITCH, J.; SCHEINER, S. M.; FOX, G. A. Propriedades e mecanismos das comunidades. In: GUREVITCH, J.; SCHEINER, S. M.; FOX, G. A. (Orgs.). Ecologia vegetal. Porto Alegre: Artmed, 2009. 
p. 205-223.

HALLÉ, F.; OLDEMAN, R. A. A.; TOMLINSON, P. B. Tropical trees and forests: an architectural analysis. Berlin: Springer-Verlang, 1978. $441 \mathrm{p}$.

IBGE. Manual técnico da vegetação brasileira. Rio de Janeiro: Fundação Instituto Brasileiro de Geografia e Estatística, 2012.274 p.

IUSS WORKING GROUP WRB. World reference base for soil resources 2014: international soil classification system for naming soils and creating legends for soil maps. Rome: FAO, 2014. 106 p. (World Soil Resources Reports, 106).

JARENKOW, J. A.; BUDKE, J. C. Padrões florísticos e análise estrutural de remanescentes de Florestas com Araucária no Brasil. In: FONSECA, C. R. et al. (Eds.). Floresta com araucária: ecologia, conservação e desenvolvimento sustentável. Ribeirão Preto: Holos, 2009. p. 113-125.

JARENKOW, J. A.; WAECHTER, J. L. Composição, estrutura e relações florísticas do componente arbóreo de uma floresta estacional no Rio Grande do Sul, Brasil. Revista Brasileira de Botânica, São Paulo, v. 24, n. 3, p. 263-272, 2001.

KLEIN, R. M. Árvores nativas da Floresta Subtropical do Alto Uruguai. Sellowia, Itajaí, v. 24, p. 9-62, 1972.

KLEIN, R. M.. Mapa fitogeográfico de Santa Catarina. In: REITZ, R. (Ed.). Flora Ilustrada Catarinense. Itajaí: Herbário Barbosa Rodrigues, 1978. 24 p.

KLEIN, R. M.. Aspectos dinâmicos da vegetação do sul do Brasil. Sellowia, Itajaí, v. 36, p. 5-54, 1984a.

KLEIN, R. M.. Meliáceas. In: REITZ, R. (Ed.). Flora Ilustrada Catarinense. Itajaí: Herbário Barbosa Rodrigues, 1984b. $138 \mathrm{p}$.

LAMPRECHT, H. Ensayo sobre unos metodos para el análisis estructural de los bosques tropicales. Acta Cientifica Venezolana, Caracas, v. 13, n. 2, p. 57-65, 1962.

LAURANCE, W. F. Hyper-disturbed parks: edge effects and the ecology of isolated rain forest reserves in tropical Australia. In:

BIERREGAARD, R. O. (Eds.). Tropical forest remnants: ecology, management, and conservation of fragmented landscape. Chicago: University of Chicago Press, 1997. p. 71-83.

LAURANCE, W. F. et al. Rain forest fragmentation and the dynamics of Amazonian tree communities. Ecology, Brooklyn, v. 79, n. 6, p. 2032-2040, 1998.

LAURANCE, W. F. et al. Rainforest fragmentation kills big trees. Nature, London, v. 404, p. 836, 2000.

LEITE, P. F. Contribuição ao conhecimento fitogeográfico do sul do Brasil. Ciência \& Ambiente, Santa Maria, n. 24, p. 51-73, 2002.

LEYSER, G. et al. Espectro de dispersão em um fragmento de transição entre Floresta Ombrófila Mista e Floresta Estacional na região do Alto Uruguai, Rio Grande do Sul, Brasil. Pesquisas, Série Botânica, São Leopoldo, n. 60, p. 355-366, 2009.

LINDENMAIER, D. S.; BUDKE, J. C. Florística, diversidade e distribuição espacial das espécies arbóreas em uma floresta estacional na bacia do rio Jacuí, sul do Brasil. Pesquisas, Série Botânica, São Leopoldo, n. 57, p. 193-216, 2006.

LORENZI, H. Árvores brasileiras: manual de identificação e cultivo de plantas arbóreas do Brasil. 5 ed. Nova Odessa: Editora Plantarum, 2009a. v. 1, 384 p.

LORENZI, H.. Árvores brasileiras: manual de identificação e cultivo de plantas arbóreas do Brasil. 3 ed. Nova Odessa: Editora Plantarum, 2009b. v. 2, 384 p.

LORENZI, H.. Árvores brasileiras: manual de identificação e cultivo de plantas arbóreas do Brasil. 1 ed. Nova Odessa: Editora Plantarum, 2009c. v. 3, 384 p.

MARCHIORI, J. N. C. Dendrologia das angiospermas: leguminosas. Santa Maria: Editora UFSM, 1997. $200 \mathrm{p}$.

MARCHIORI, J. N. C.. Dendrologia das angiospermas: das bixáceas às rosáceas. Santa Maria: Editora UFSM, 2000. $240 \mathrm{p}$.

MARTINS, S. V. Técnicas de restauração florestal de áreas degradadas. In:

(Org.). Recuperação

de áreas degradadas: ações em áreas de preservação permanente, voçorocas, taludes rodoviários e de mineração. Viçosa: Aprenda Fácil, 2009. p. 63-121.

MARTINS, S. V. ; NETO, A. M.; RIBEIRO, T. M. Uma abordagem sobre diversidade e técnicas de 
restauração ecológica. In: (Ed.). Restauração ecológica de ecossistemas degradados. Viçosa:

Editora UFV, 2012. p. 17-40.

MULLER-DOMBOIS, D.; ELLENBERG, H. Aims and of vegetation ecology. New York: John Wiley \& Sons, 1974. $547 \mathrm{p}$.

ODA-SOUZA, M. et al. Influência do tamanho e forma da unidade amostral sobre a estrutura de dependência espacial em quatro formações florestais do estado de São Paulo. Floresta, Curitiba, v. 40, n. 4, p. 849-860, 2010

PANDOLFO, C. et al. Atlas climatológico do estado de Santa Catarina. Florianópolis: Epagri, 2002. PEDRALLI, G. Lauráceas 6. Nectandra. In: REITZ, R. (Ed.). Flora Ilustrada Catarinense. Itajaí: Herbário Barbosa Rodrigues, $1987.93 \mathrm{p}$.

PINTO, E. J. A. (Coord.). Atlas pluviométrico do Brasil: isoietas anuais médias. Brasília: CPRM, 2011. RAMBO, B. Migration routes of the South Brazilian rain forest. Pesquisas, Série Botânica, São Leopoldo, v. 12, p. 1-54, 1961.

REITZ, R.; KLEIN, R. M.; REIS, A. Projeto Madeira de Santa Catarina. Sellowia, Itajaí, v. 28, 1978.

REITZ, R.; KLEIN, R. M.; REIS, A.. Projeto madeira do Rio Grande do Sul. Itajaí: Herbário Barbosa Rodrigues, $1988.525 \mathrm{p}$.

RICHARDS, P. W. The tropical rain forest: an ecological study. Cambridge: Cambridge University Press, 1996. $600 \mathrm{p}$.

RUSCHEL, A. R. et al. Evolução do uso e valorização das espécies madeiráveis da Floresta Estacional Decidual do Alto-Uruguai, SC. Ciência Florestal, Santa Maria, v. 13, n. 1, p. 153-166, 2003.

RUSCHEL, A. R. et al. et al. Valuation and characterization of the timber species in remnants of the Alto Uruguay river ecosystem, southern Brazil. Forest Ecology and Management, Amsterdam, v. 217, p. 103116, 2005.

RUSCHEL, A. R. et al.; GUERRA, M. P.; NODARI, R. O. Estrutura e composição florística de dois fragmentos da Floresta Estacional Decidual do Alto-uruguai, SC. Ciência Florestal, Santa Maria, v. 19, n. 2, p. 225-236, 2009.

SANQUETTA, C. R. et al. Estrutura vertical de um fragmento de Floresta Ombrófila Mista no centro-sul do Paraná. Ciências Exatas e Naturais, Guarapuava, v. 3, n. 1, p. 59-73, 2001.

SCHNEIDER, G.; ROCHA, F. S. Levantamento florístico e fitossociológico do componente arbóreo de um fragmento de Floresta Estacional Decidual em São Miguel do Oeste, Santa Catarina. Biotemas, Florianópolis, v. 27, n. 2, p. 43-55, 2014.

SCIPIONI, M. C. et al. Fitossociologia em fragmento florestal no noroeste do estado do Rio Grande do Sul. Ciência Florestal, Santa Maria, v. 21, n. 3, p. 409-419, 2011.

SOCIETY FOR ECOLOGICAL RESTORATION. The SER International primer on ecological restoration. Tucson: Society for Ecological Restoration International, Sciense \& Policy Working Group, 2004. Disponível em: <http://www.ser.org/docs/default-document-library/english.pdf $>$. Acesso em: 27 ago. 2013.

SMITH, L. B.; DOWNS, R. J.; KLEIN, R. M. Euforbiáceas. In: REITZ, R. (Ed.). Flora Ilustrada Catarinense. Itajaí: Herbário Barbosa Rodrigues, 1988. 408 p.

SOUZA, J. M. et al. Sistema de mapas para a web do Inventário Florístico Florestal de Santa Catarina. Epagri/Ciram, 2012. Disponível em: <http://ciram.epagri.sc.gov.br/siffsc/>. Acesso em: 21 ago. 2013.

SÜHS, R. B.; BUDKE, J. C. Spatial distribution, association patterns and richness of tree species in a seasonal forest from Serra Geral formation, southern Brazil. Acta Botanica Brasilica, Belo Horizonte, v. 25, n. 3, p. 605-617, 2011.

VELOSO, H. P.; RANGEL FILHO, A. L. R.; LIMA, J. C. A. Classificação da vegetação brasileira, adaptada a um sistema universal. Rio de Janeiro: IBGE, 1991.

VIBRANS, A. C. et al. (Eds.). Inventário florístico florestal de Santa Catarina: Floresta Estacional Decidual. Blumenau: Edifurb, 2012a. v. 2, 336 p.

VIBRANS, A. C. et al. Extensão original e remanescentes da Floresta Estacional Decidual em Santa Catarina. In: et al. (Eds.). Inventário florístico florestal de Santa Catarina: Floresta Estacional Decidual. Blumenau: Edifurb, 2012b. v. 2, p. 25-32.

VIBRANS, A. C. et al. Extensão original e remanescentes da Floresta Ombrófila Mista em Santa Catarina. 
In: et al. (Eds.). Inventário florístico florestal de Santa Catarina: Floresta Ombrófila Mista. Blumenau: Edifurb, 2012c. v. 3, p. 25-32.

VIBRANS, A. C. et al. Extensão original e remanescentes da Floresta Ombrófila Densa em Santa Catarina. In: et al. (Eds.). Inventário florístico florestal de Santa Catarina: Floresta Ombrófila Densa. Blumenau: Edifurb, 2013a. v. 4, p. 25-36.

VIBRANS, A. C. et al. Using satellite image-based maps and ground inventory data to estimate the area of the remaining Atlantic forest in the Brazilian state of Santa Catarina. Remote Sensing of Environment, New York, v. 130, p. 87-95, 2013 b.

VIBRANS, A. C.; GASPER, A. L.; MÜLLER, J. J. V. Para que inventariar florestas? Reflexões sobre a finalidade do inventário florístico florestal de Santa Catarina. Estudos Ambientais, Blumenau, v. 14, n. 1 esp., p. 6-13, 2012d

WILLIAMS-LIMERA, G. Vegetative structure and environmental conditions of forest edges in Panama. Journal of Ecology, Londres, v. 78, p. 356-373, 1990. 